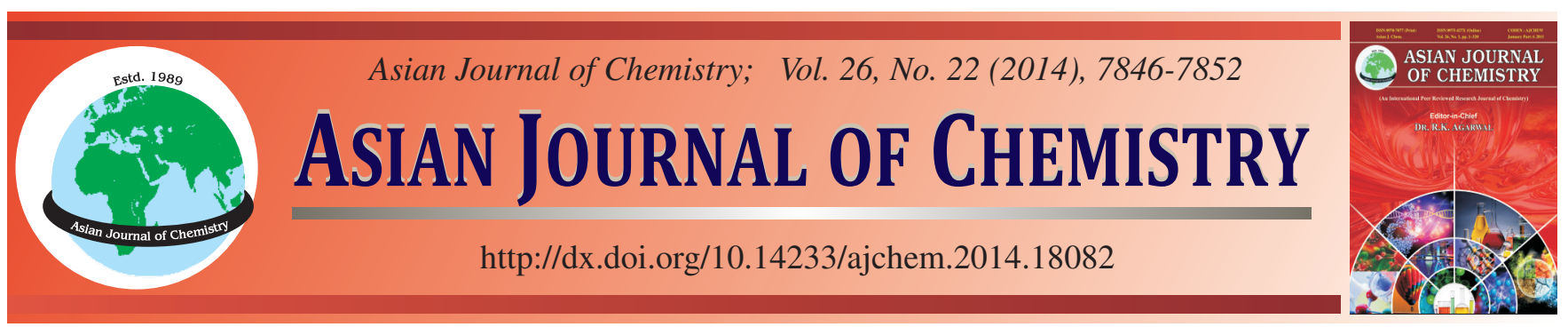

\title{
Synthesis and Characterization of New Aromatic Polyesters Derived from New Aromatic Di- and Tri Hydroxyl Monomers with 4-Phenylenediacrylic Acid and Malonic Acid
}

\author{
Mohammed A. Mutar
}

Department of Chemistry, College of Education, University of Al-Qadisyia, Al-Qadisyia, Iraq

Corresponding author: E-mail: mohammeddw73@gmail.com

\begin{abstract}
In the present work, six new aromatic polyesters (PE1-PE6) have been synthesized in high yields from the polycondensation between diand tri hydroxyl monomers containing methylene unit, Schiff-base linkages and pyridine heterocyclic ring with 4-phenylenediacrylic acid and malonic acid using dibutyltin dilaurate as catalyst. The structure analysis of the polymers has been carried out by using FT-IR and ${ }^{1} \mathrm{H}$ NMR spectroscopy. The monomers were characterized by FTIR and ${ }^{1} \mathrm{H}$ NMR. FT-IR technique confirmed the esterification of di and tri hydroxyl monomers by the acid in all the polymers.
\end{abstract}

Keywords: Synthesis, Aromatic polyesters, 4-Phenylenediacrylic acid, Malonic acid.

\section{INTRODUCTION}

The family of polyesters comprises all polymers with ester functional groups in the polymer backbone. The chemistry of the structural units connecting the ester group can be varied over an immensely broad range, making the polyesters a diverse group covering labile biomedical matrices to liquid crystals, fibers and temperature resistant performance materials, etc. Polyesters are the first family of synthetic condensation polymers ${ }^{1-3}$. Polyesters can typically be formed by a stepwise condensation reaction from difunctional monomers such as diols and acids ${ }^{2}$.

Recently, Takasu et $a l .{ }^{4}$ and Liu et al..$^{5}$ reported that the $\mathrm{HfCl}_{4}(\mathrm{THF})_{2}$ complex more efficiently catalyzed the direct polycondensation of diols and dicarboxylic acid compounds, in which the procedure was a solution polycondensation in $o$-xylene with reflux (about $144^{\circ} \mathrm{C}$ ) for $24 \mathrm{~h}$. Ober et al. ${ }^{6}$ synthesized polyesters from dihydroxy compounds by polymerizing diacid chlorides at $500{ }^{\circ} \mathrm{C}$ for $24 \mathrm{~h}$ in inert atmosphere using pyridine as proton acceptor. Polyesters were prepared by Ramireddy and coworkers ${ }^{7}$ by using pyridine as catalyst and $\mathrm{HCl}$ scavenger, which was produced as a byproduct of the esterification reaction with acid chlorides. The reaction was allowed to proceed for $48 \mathrm{~h}$ at room temperature in dry nitrogen. Polyesteramides with exact desired structure can be synthesized from monomers with proper structure and functional groups. Sek et al. ${ }^{8}$ synthesized monomers and carried out the polymerization reactions in boiling chlorobenzene at $130{ }^{\circ} \mathrm{C}$ in presence of pyridine in argon atmosphere .The reaction variables have strong influence on molecular weight of the polymers as observed by Economy ${ }^{9}$.

Since the reaction parameters have prominent influence on the rate of reaction and molecular weight of the polymers, the polycondensation reaction was carried out at different temperature with varying monomer concentration in different solvent system over a range of reaction period and the yield and the molecular weight of the resulting polymers were studied. The polymers, synthesized by the condensation of aromatic diols and diacids through a low temperature procedure, were subjected to Fourier transform infrared (FTIR) spectroscopy to study the chemical constituents of the molecules and the molecular interaction among the polymer chains. The chemical composition of the polymers can be determined by the definite absorption bands in the spectrum.

The analyses of the thermal properties of the polyesters have been made by the help of the thermograms obtained from the DSC studies. Furthermore, polyesters are known to possess enhanced thermal stabilities ${ }^{10}$.

In the present work, a series of new aromatic polyesters containing both methylene unit, Schiff-base linkages and pyridine hetero cyclic ring have been synthesized in high yields from the polycondensation between di- and tri hydroxyl monomers with 4-phenylenediacrylic acid and malonic acid using dibutyltin dilaurate as catalyst.

\section{EXPERIMENTAL}

Fourier transform infrared (FTIR) spectra were recorded on a Shimadzu-FTIR-8400S spectrometer (Japan) with $\mathrm{KBr}$ 
pellets in the optical range of $4000-400 \mathrm{~cm}^{-1} .{ }^{1} \mathrm{H}$ NMR spectra were registered using a Bruker, $250 \mathrm{Mhz}$, spectrometer, at polymer laboratories Co Iran using DMSO as a solvent. The solubility of the polymers was determined with $(0.01 \mathrm{~g})$ of polyester in $(2 \mathrm{~mL})$ of a solvent.

Absolute methanol, acetic acid, ammonium acetate, dibutyltin dilaurate, all from (BDH/England); dichloromethane, hexane, procured from (BIOSOLVE). Hydrochloric acid, salicylaldehyde, benzaldehyde all from (HiMedia); diethyl ether obtained from (IGCC/England) while phenol, p-aminophenol, 4-chlorobenzaldehyde, glacial acetic acid, piperidine, pyridine, terephthalaldehyde, dimethyl sulphoxide, $m$-cresol, N,N-dimethylacetamide, 4-(dimethyl amino)benzaldehyde, $p$-hydroxyacetophenone, tetrahydrofurane obtained from Merck. Absolute ethanol from (Scharlab S.L), malonic acid and N,N-dimethylformamide from Aldrich.

Synthesis of 1,1,1-tris(4-hydroxyphenyl)ethane (M1): A mixture of 4-hydroxy acetophenone $(2.72 \mathrm{~g}, 20 \mathrm{mmol})$, phenol (4 g, $42 \mathrm{mmol}), \mathrm{HCl}$ catalyst (37.5 g) and thioglycolic acid $(0.5 \mathrm{~g})$ promoter were placed in a three necked-round bottom flask equipped with a condenser, mechanical stirrer and thermometer and kept in a thermostat bath at $60{ }^{\circ} \mathrm{C}$ for $6 \mathrm{~h}$. After a definite period of time, the reaction mixture was transferred to cold water to quench the reaction. Then, the product was washed, dried ${ }^{11}$ to yield $5 \mathrm{~g}(82 \% \mathrm{wt})$ of brown powder (Scheme-I). The monomer has characterized by FTIR.

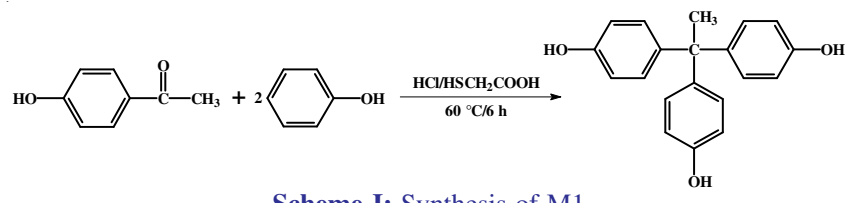

Scheme-I: Synthesis of M1

Synthesis of M2: This monomer was prepared by the condensation of terephthalaldehyde $(1.34 \mathrm{~g}, 10 \mathrm{mmol})$ and p-aminophenol (2.2 g, $20 \mathrm{mmol})$ in $15 \mathrm{~mL}$ of methanol, by boiling the mixture under reflux at $120^{\circ} \mathrm{C}$ for $3 \mathrm{~h}$. The precipitated was filtered and recrystallized from methanol and dried in a vacuum desiccators ${ }^{12}$ to yielding $2.5 \mathrm{~g}(79 \% \mathrm{wt})$ of verylight yellow crystals. m.p. $205-210^{\circ} \mathrm{C}$ (Scheme-II). This monomer was characterized by FTIR and ${ }^{1} \mathrm{H}$ NMR spectra.

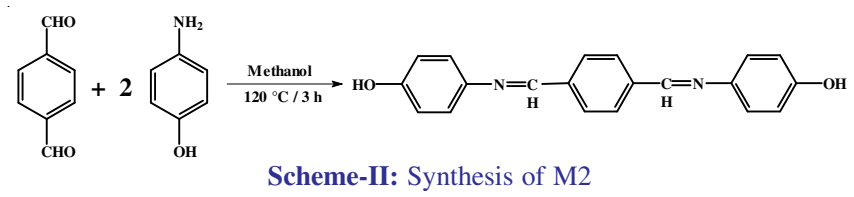

General synthesis of M3, M4, M5, M6: In a roundbottomed flask $(150 \mathrm{~mL})$ equipped with a reflux condenser, a mixture of aldehyde derivative $(10 \mathrm{mmol})$, that showed in (Table-1), p-hydroxyacetophenone (2.72 g, $20 \mathrm{mmol})$, ammonium acetate $(7.5 \mathrm{~g})$ and glacial acetic acid $(20 \mathrm{~mL})$ was refluxed at $140-142{ }^{\circ} \mathrm{C}$ for $2 \mathrm{~h}$. Upon cooling, crystals separated, which were filtered and washed first with acetic acid $(50 \%)$ and then with cold ethanol. These product crystals were recrystallized from absolute ethanol and then dried at $60{ }^{\circ} \mathrm{C}$ under vacuum ${ }^{13,14}$.

Synthesis of M3: There are several methods for preparation of the pyridine ring. Modified Chichibabin method is one of the best methods for the preparation of a pyridine ring ${ }^{15,16}$, which offers advantages such as good yield, available starting material and potential for introducing different substituent's in the pyridine ring.

M3 is prepared by the condensation of one molecule of benzaldehyde with two molecules of $p$-hydroxyacetophenone in the presence of ammonium acetate and glacial acetic acid at $140-142^{\circ} \mathrm{C}$ for $2 \mathrm{~h}$ (Scheme-III). This monomer was characterized by FTIR.

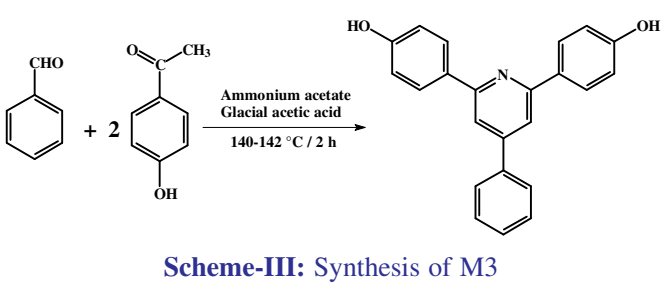

Synthesis of M4: M4 is prepared by the condensation of one molecule of 4-chlorobenzaldehyde with two molecules of $p$-hydroxyacetophenone in the presence of ammonium acetate and glacial acetic acid at $140-142^{\circ} \mathrm{C}$ for $2 \mathrm{~h}$ (SchemeIV). This monomer was characterized by FTIR.

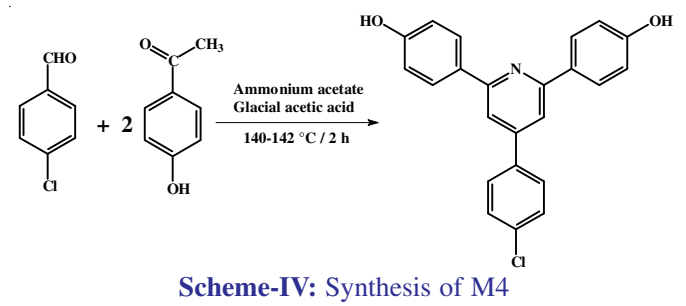

Synthesis of M5: M5 is prepared by the condensation of one molecule of 4-(dimethylamino)benzaldehyde with two molecules of $p$-hydroxyacetophenone in the presence of ammonium acetate and glacial acetic acid at $140-142{ }^{\circ} \mathrm{C}$ for $2 \mathrm{~h}$ (Scheme-V). This monomer was characterized by FTIR.

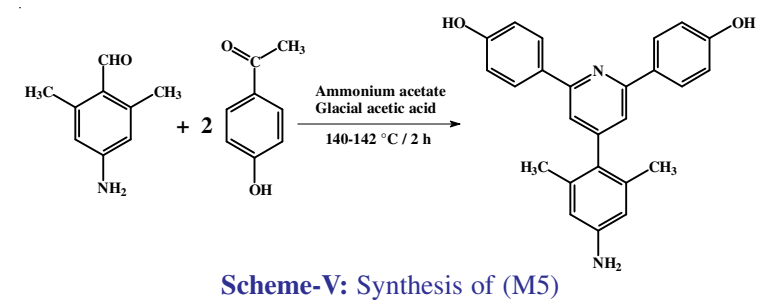

TABLE-1

SYNTHESIS OF MONOMERS (M3, M4, M5, M6)

\begin{tabular}{|c|c|c|c|c|c|c|}
\hline \multirow{2}{*}{ Monomers } & \multicolumn{2}{|l|}{ Substance } & \multirow{2}{*}{$\begin{array}{c}\text { Weight of } \\
\text { monomer }(\mathrm{g})\end{array}$} & \multirow{2}{*}{$\begin{array}{c}\text { Yield } \\
(\% \text { wt })\end{array}$} & \multirow{2}{*}{ Colour } & \multirow{2}{*}{ m.p. $\left({ }^{\circ} \mathrm{C}\right)$} \\
\hline & Aldehyde derivative & Weight (g) & & & & \\
\hline M3 & Benzaldehyde & 1.06 & 2.6 & 77 & Greenish yellow & $278-282$ \\
\hline M4 & 4-Chloro benzaldehyde & 1.41 & 2.94 & 79 & Blackish brown & Viscous liquid \\
\hline M5 & 4-(Dimethylamino) benzaldehyde & 1.49 & 2.97 & 78 & Blackish red & Viscous liquid \\
\hline M6 & Salicylaldehyde & 1.22 & 2.80 & 79 & Reddish brown & $205-210$ \\
\hline
\end{tabular}


TABLE-2

SYNTHESIS OF POLYESTERS (PE1-PE6)

\begin{tabular}{|c|c|c|c|c|c|c|}
\hline \multirow{2}{*}{ Polyesters } & \multicolumn{2}{|l|}{ Monomers } & \multirow{2}{*}{$\begin{array}{c}\text { Diacid } \\
(\mathrm{g} / \mathrm{mmol})\end{array}$} & \multirow{2}{*}{$\begin{array}{c}\text { Dihydroxy } \\
(\mathrm{g} / \mathrm{mmol})\end{array}$} & \multirow{2}{*}{$\begin{array}{c}\text { Yield } \\
(\% \mathrm{wt})\end{array}$} & \multirow{2}{*}{ Colour } \\
\hline & Diacid & Dihydroxy & & & & \\
\hline PE1 & Malonic acid & M1 & $2.08 / 20$ & $3.06 / 10$ & 76 & Light brown \\
\hline PE2 & Malonic acid & M2 & $1.04 / 10$ & $3.16 / 10$ & 79 & Light pink \\
\hline PE3 & $p$-Phenylenediacrylic acid & M3 & $2.18 / 10$ & $3.39 / 10$ & 77 & Light yellow \\
\hline PE4 & $p$-Phenylenediacrylic acid & M4 & $2.18 / 10$ & $3.72 / 10$ & 78 & Black \\
\hline PE5 & $p$-Phenylenediacrylic acid & M5 & $2.18 / 10$ & $3.82 / 10$ & 79 & Brown \\
\hline PE6 & $p$-Phenylenediacrylic acid & M6 & $4.36 / 20$ & $3.55 / 10$ & 79 & Deep brown \\
\hline
\end{tabular}

Synthesis of M6: M6 is prepared by the condensation of one molecule of salicylaldehyde with two molecules of $p$ hydroxyacetophenone in the presence of ammonium acetate and glacial acetic acid at $140-142{ }^{\circ} \mathrm{C}$ for $2 \mathrm{~h}$. This monomer was characterized by FTIR and ${ }^{1} \mathrm{H}$ NMR spectra.

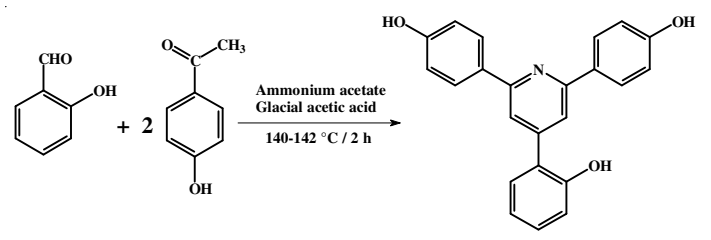

Scheme-VI: Synthesis of M6

Synthesis of polyesters (PE1- PE6): In this section, we used polycondensation method for synthesis of a series of two new polyesters from the direct polycondensation reaction of malonic acid with two new different aromatic dihydroxy monomers (M1, M2), respectively and four new polyesters from the direct polycondensation reaction of $p$-phenylenediacrylic acid with four new different aromatic dihydroxy monomers (M3, M4, M5 and M6), respectively, by using the dibutyltin dilaurate catalyst [0.15 wt. (\%)] (Scheme-VII) (Table-2). The materials were dried under vacuum at $50{ }^{\circ} \mathrm{C}$ giving rise to the $\mathrm{PE}$ series. The materials were obtained as powders ${ }^{17}$. These polymers have a soft segment such as methylene unit, vinyl moiety and Schiff-base groups and pyridine heterocyclic ring in main chain for improving solubility in organic solvents. These polyesters were characterized by FTIR and ${ }^{1} \mathrm{H}$ NMR spectra.

\section{RESULTS AND DISCUSSION}

The FTIR spectrum of M1 as shown in (Fig. 1) which indicates absorption band at $\left(3271 \mathrm{~cm}^{-1}\right)$ to (-OH group), (3062 $\mathrm{cm}^{-1}$ ) to (aromatic -CH Str), $\left(2985 \mathrm{~cm}^{-1}\right)$ to (aliphatic -CH Str) and absorption bands around (1666-1512 $\left.\mathrm{cm}^{-1}\right)$ show the presence of the aromatic ring.

The FTIR spectrum of (M2 Schiff-Base) is shown in (Fig. 2) which indicates absorption bands at $\left(3311 \mathrm{~cm}^{-1}\right)$ to (-OH group), (3078 $\left.\mathrm{cm}^{-1}\right)$ to (aromatic -CH stretching), (2922 $\mathrm{cm}^{-1}$ ) to (aliphatic-CH stretching) and absorption bands around $\left(1612-1546 \mathrm{~cm}^{-1}\right)$ show the presence of the aromatic ring.

${ }^{1} \mathrm{H}$ NMR spectrum of M2, is shown in Fig. 3 assigns the following chemical shifts; $\delta(2.5) \mathrm{ppm}$ for DMSO, $\delta$ (3.5) ppm $(\mathrm{s}, 2 \mathrm{H})$ for $\mathrm{C}-\mathrm{H}, \delta(3.4)(\mathrm{s}, 2 \mathrm{H})$ for $\mathrm{OH}$ group, $\delta(6.8-8.2)$ $\operatorname{ppm}(\mathrm{s}, 12 \mathrm{H})$ for Ar-H group.

The FTIR spectrum of M3 as shown in (Fig. 4) which indicates absorption band at $\left(3366 \mathrm{~cm}^{-1}\right)$ to (-OH group), (3148 $\mathrm{cm}^{-1}$ ) to (aromatic $-\mathrm{CH}$ stretching), absorption bands around

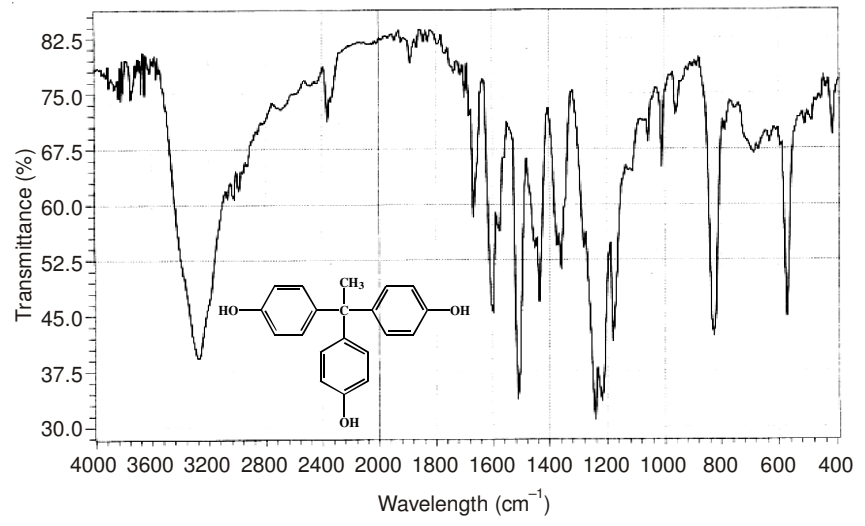

Fig. 1. FTIR spectrum of M1

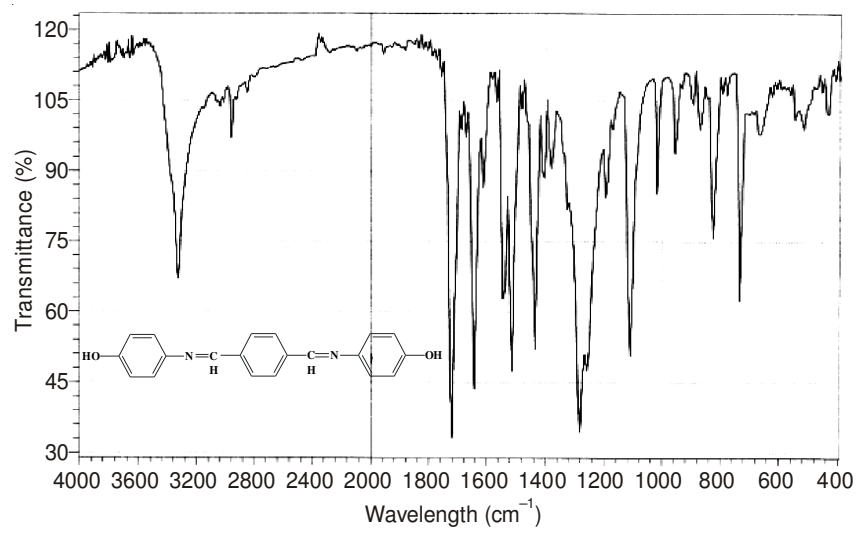

Fig. 2. FTIR spectrum of M2

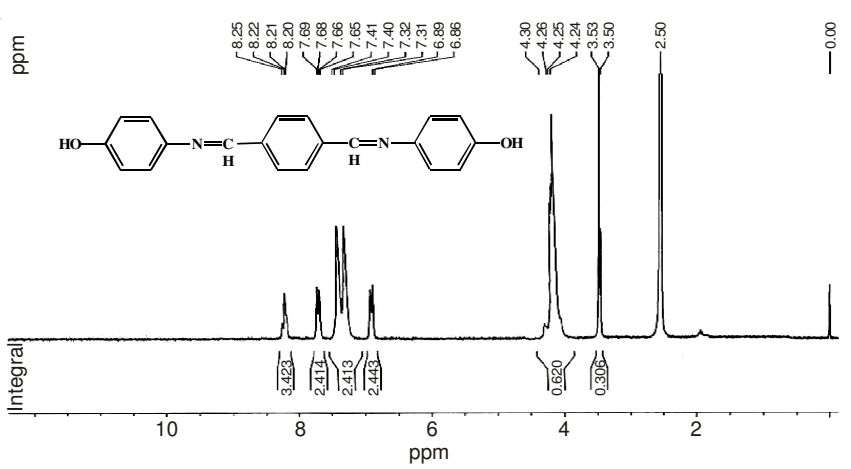

Fig. $3 .{ }^{1} \mathrm{H}$ NMR spectrum of M2

(1671-1656 $\left.\mathrm{cm}^{-1}\right)$ show the presence of the aromatic ring and (1590-1523 $\left.\mathrm{cm}^{-1}\right)$ to heteroaromatic ring $(\mathrm{C}=\mathrm{N})$.

The FTIR spectrum of M4 as shown in (Fig. 5) which indicates absorption band at $\left(3377 \mathrm{~cm}^{-1}\right)$ to (-OH group), (3138 $\mathrm{cm}^{-1}$ ) to (aromatic $-\mathrm{CH}$ stretching), absorption bands around 

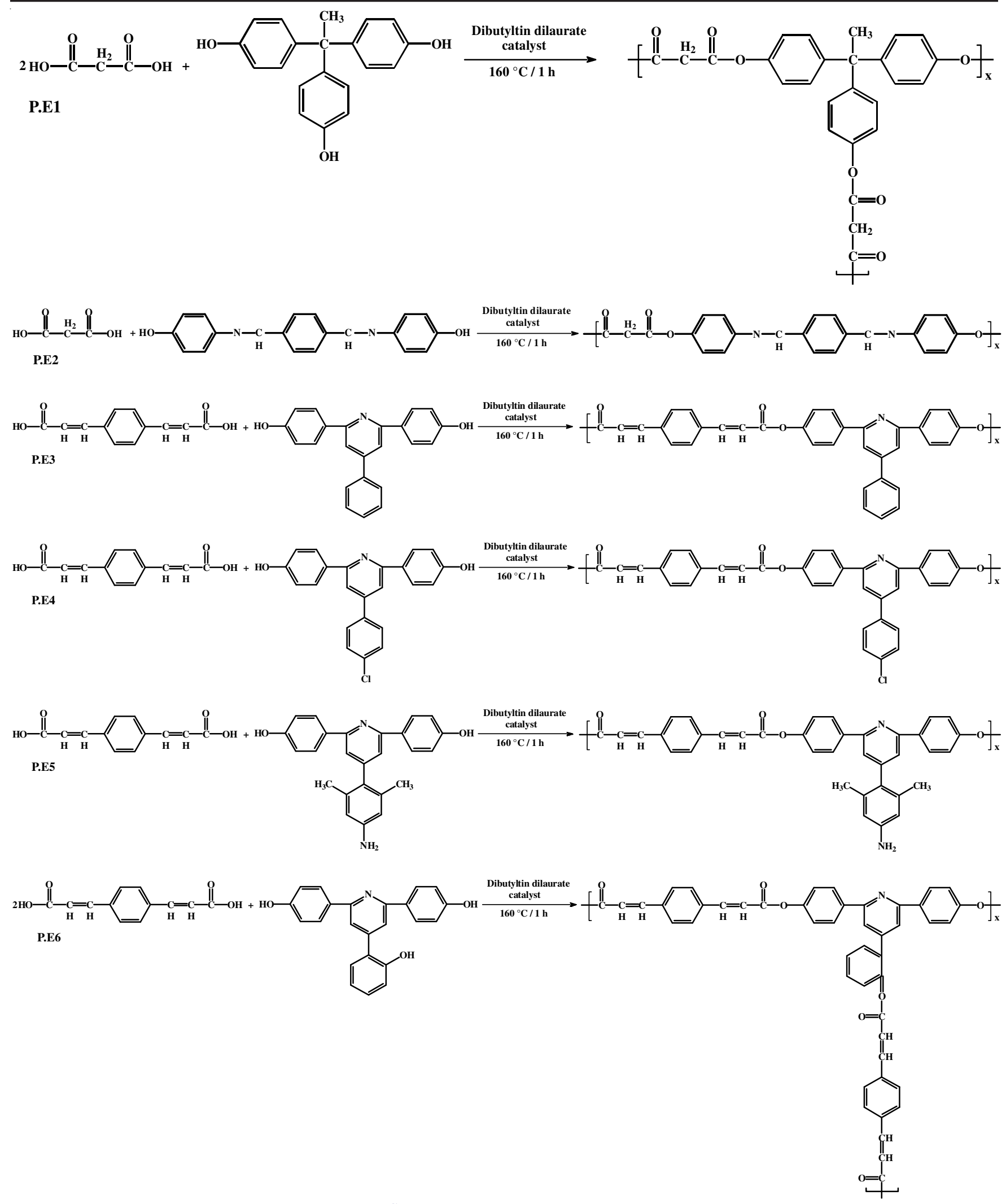

Scheme-VII: Synthesis of PE1-PE6

(1670-1654 $\left.\mathrm{cm}^{-1}\right)$ show the presence of the aromatic ring, $\left(1592-1521 \mathrm{~cm}^{-1}\right)$ to heteroaromatic $\operatorname{ring}(\mathrm{C}=\mathrm{N})$ and $\left(811 \mathrm{~cm}^{-1}\right)$ to $(\mathrm{C}-\mathrm{Cl})$.

The FTIR spectrum of M5 as shown in (Fig. 6) which indicates absorption bands at $\left(3366 \mathrm{~cm}^{-1}\right)$ to $\left(-\mathrm{NH}_{2}\right.$ group $),(3311$ $\mathrm{cm}^{-1}$ ) to (-OH group), (3044 $\left.\mathrm{cm}^{-1}\right)$ to (aromatic $-\mathrm{CH}$ stretching), $\left(2806 \mathrm{~cm}^{-1}\right)$ to (aliphatic-CH stretching), absorption bands around $\left(1668-1648 \mathrm{~cm}^{-1}\right)$ show the presence of the aromatic rings and $\left(1587-1517 \mathrm{~cm}^{-1}\right)$ to heteroaromatic ring $(\mathrm{C}=\mathrm{N})$.

The FTIR spectrum of M6 as shown in (Fig. 7) which indicates absorption band at $\left(3356 \mathrm{~cm}^{-1}\right)$ to (-OH group), (3138 $\mathrm{cm}^{-1}$ ) to (aromatic $-\mathrm{CH}$ stretching), absorption bands around 


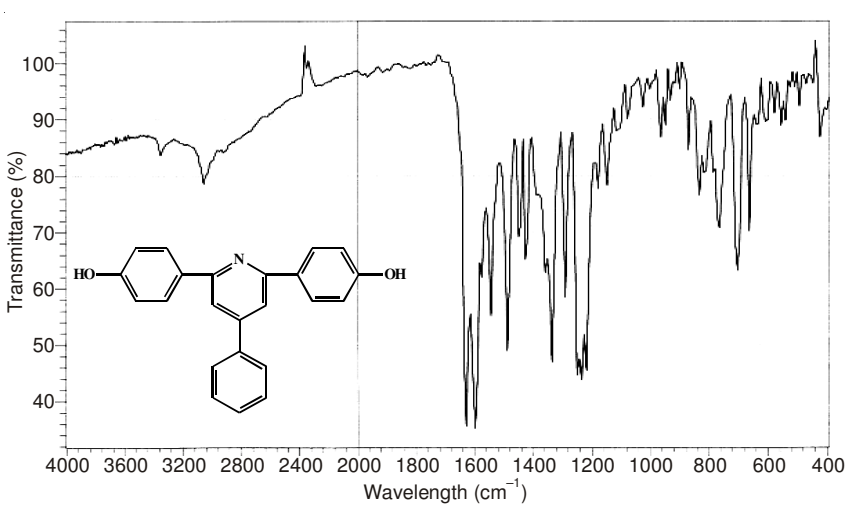

Fig. 4. FTIR spectrum of M3

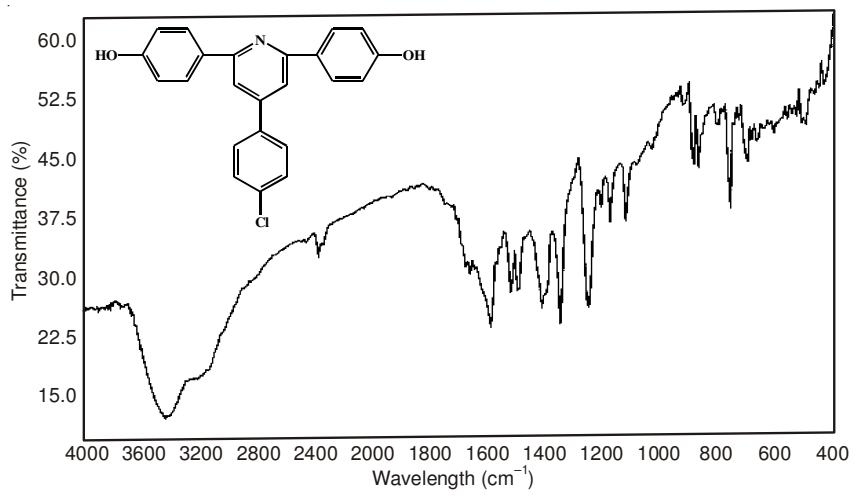

Fig. 5. FTIR spectrum of M4

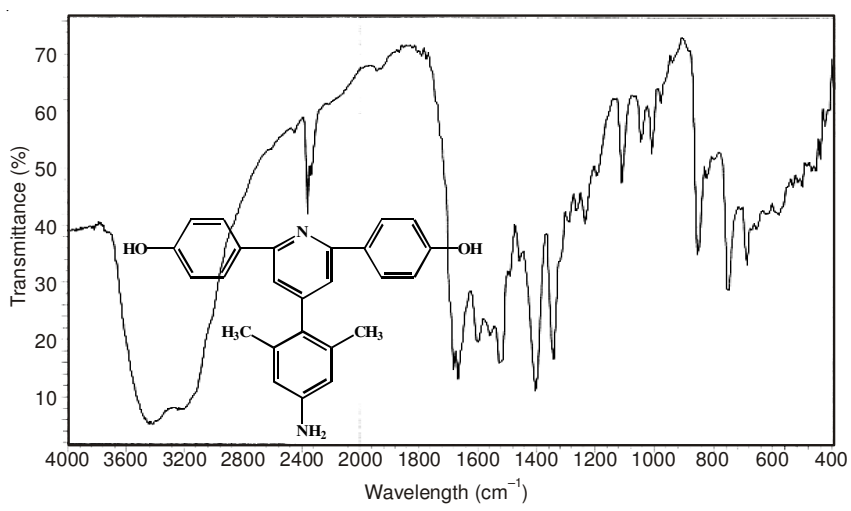

Fig. 6. FTIR spectrum of M5

$\left(1679-1658 \mathrm{~cm}^{-1}\right)$ show the presence of the aromatic ring and $\left(1599-1527 \mathrm{~cm}^{-1}\right)$ to heteroaromatic ring $(\mathrm{C}=\mathrm{N})$.

${ }^{1} \mathrm{H}$ NMR spectrum of M6, is shown in Fig. 8 assigns the following chemical shifts; $\delta(2.5) \mathrm{ppm}$ for DMSO, $\delta(4.5) \mathrm{ppm}$ $(\mathrm{s}, 3 \mathrm{H})$ for $\mathrm{OH}, \delta(5.7), \delta(6.5-8.5) \mathrm{ppm}(\mathrm{s}, 14 \mathrm{H})$ for $\mathrm{Ar}-\mathrm{H}$ group.

\section{Characterization of polyesters (PE1-PE6)}

FTIR spectrum of PE1: The FTIR spectrum of PE1 as shown in (Fig. 9) which indicates absorption band at (3070 $\left.\mathrm{cm}^{-1}\right)$ to (aromatic $\left.-\mathrm{CH} \mathrm{str}\right),\left(2989 \mathrm{~cm}^{-1}\right)$ to (aliphatic $-\mathrm{CH} \mathrm{str}$ ), $\left(1789-1766 \mathrm{~cm}^{-1}\right)$ to $(-\mathrm{C}=\mathrm{O} \mathrm{str}$, ester $),\left(1100 \mathrm{~cm}^{-1}-\mathrm{C}-\mathrm{O} \mathrm{str}\right.$, ester) and absorption bands around (1646-1532 $\left.\mathrm{cm}^{-1}\right)$ show the presence of the aromatic ring.

FTIR spectrum of PE2: The FTIR spectrum of PE2 as shown in (Fig. 10) which indicates absorption band at (3066 $\mathrm{cm}^{-1}$ ) to (aromatic-CH Str), $\left(2988 \mathrm{~cm}^{-1}\right)$ to (aliphatic $-\mathrm{CH} \mathrm{Str}$ ),

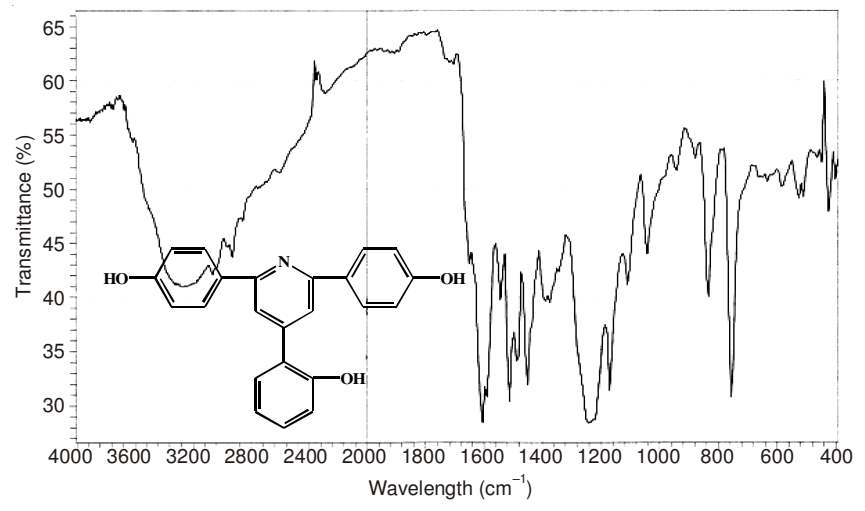

Fig. 7. FTIR spectrum of M6

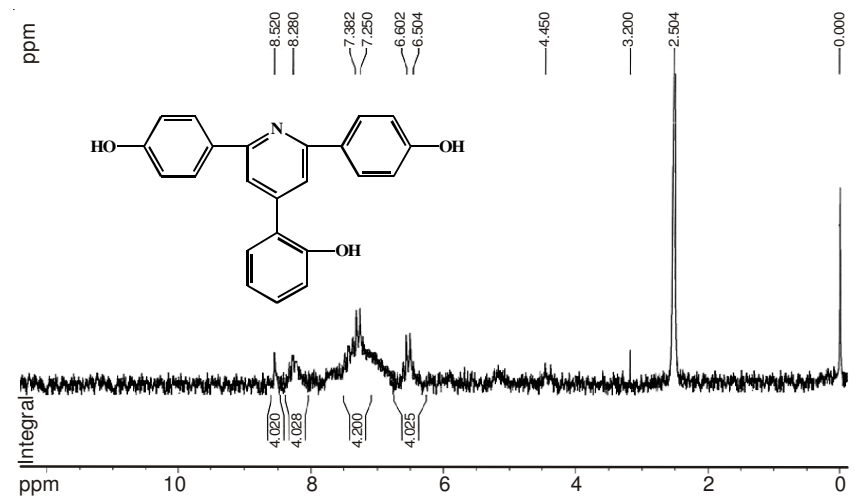

Fig. 8. ${ }^{1} \mathrm{H}$ NMR spectrum of M6

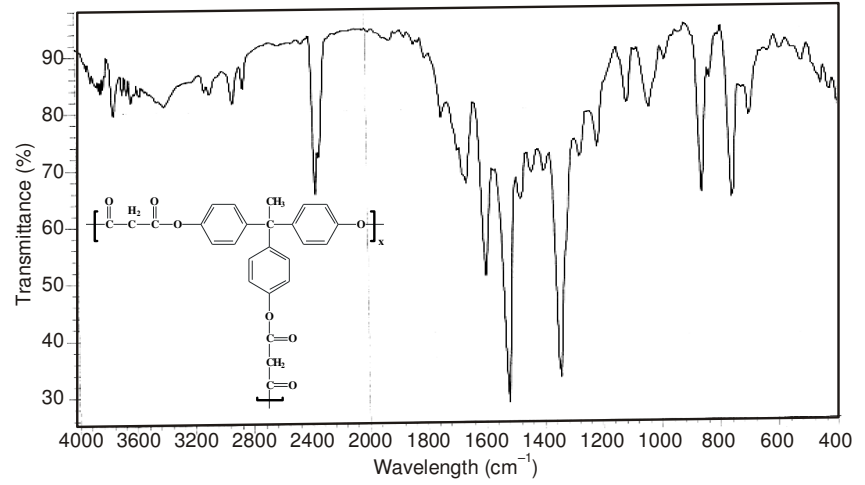

Fig. 9. FTIR spectrum of PE1

(1779-1756 $\left.\mathrm{cm}^{-1}\right)$ to (-C=O Str, ester), $\left(1108 \mathrm{~cm}^{-1}-\mathrm{C}-\mathrm{O}\right.$ Str, ester) and absorption bands around $\left(1635-1530 \mathrm{~cm}^{-1}\right)$ show the presence of the aromatic ring.

FTIR spectrum of PE3: The FTIR spectrum of PE3 as shown in (Fig. 11) which indicates absorption band at (3135 $\mathrm{cm}^{-1}$ ) to (aromatic - $\mathrm{CH}$ stretching), absorption bands around (1673-1650 $\left.\mathrm{cm}^{-1}\right)$ show the presence of the aromatic ring, (1533 $\left.\mathrm{cm}^{-1}\right)$ to vinyl segment, $\left(1762-1752 \mathrm{~cm}^{-1}\right)$ to $(-\mathrm{C}=\mathrm{O}$ str, ester $)$, $\left(1102 \mathrm{~cm}^{-1}-\mathrm{C}-\mathrm{O} \mathrm{str}\right.$, ester) and $\left(1588-1522 \mathrm{~cm}^{-1}\right)$ to heteroaromatic $\operatorname{ring}(\mathrm{C}=\mathrm{N})$.

FTIR spectrum of PE4: The FTIR spectrum of (PE4) as shown in (Fig. 12) which indicates absorption band at (3119 $\mathrm{cm}^{-1}$ ) to (aromatic $-\mathrm{CH}$ stretching), absorption bands around (1669-1649 $\left.\mathrm{cm}^{-1}\right)$ show the presence of the aromatic ring, (1537 $\left.\mathrm{cm}^{-1}\right)$ to vinyl segment, $\left(1781-1749 \mathrm{~cm}^{-1}\right)$ to $(-\mathrm{C}=\mathrm{O}$ str, ester $)$, $\left(1155 \mathrm{~cm}^{-1}-\mathrm{C}-\mathrm{O}\right.$ str, ester $),\left(1583-1524 \mathrm{~cm}^{-1}\right)$ to heteroaromatic $\operatorname{ring}(\mathrm{C}=\mathrm{N})$ and $\left(796 \mathrm{~cm}^{-1}\right)$ to $(\mathrm{C}-\mathrm{Cl})$. 


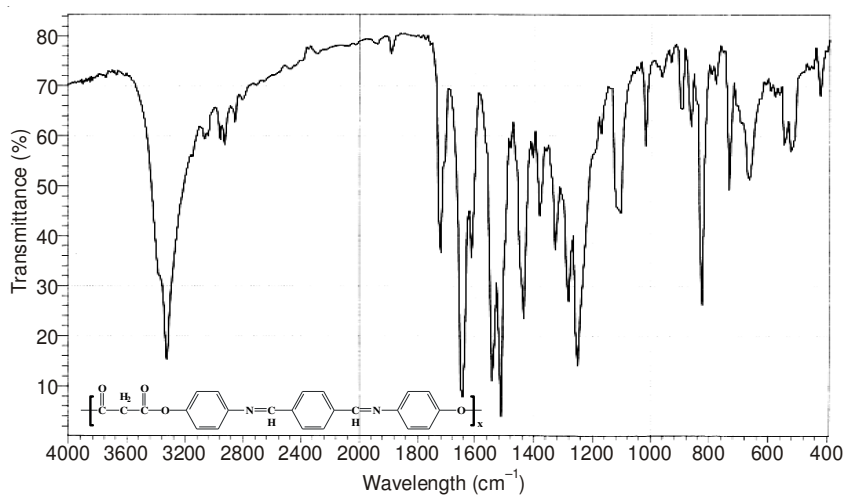

Fig. 10. FTIR spectrum of PE2

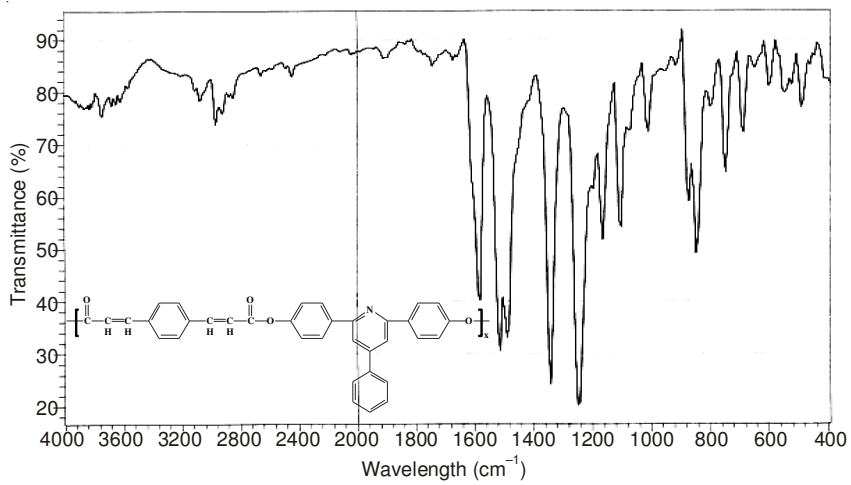

Fig. 11. FTIR spectrum of PE3

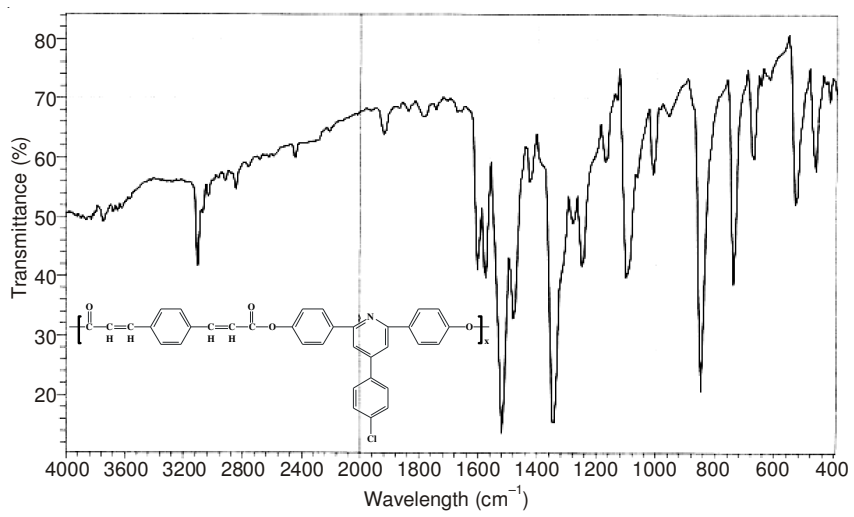

Fig. 12. FTIR spectrum of PE4

FTIR spectrum of PE5: The FTIR spectrum of PE5 as shown in (Fig. 13) which indicates absorption band at (3362 $\left.\mathrm{cm}^{-1}\right)$ to $\left(-\mathrm{NH}_{2}\right.$ group), $\left(3112 \mathrm{~cm}^{-1}\right)$ to (aromatic $-\mathrm{CH}$ stretching), (2812 $\left.\mathrm{cm}^{-1}\right)$ to (aliphatic -CH stretching), absorption bands around $\left(1642-1659 \mathrm{~cm}^{-1}\right)$ show the presence of the aromatic ring, $\left(1532 \mathrm{~cm}^{-1}\right)$ to vinyl segment, $\left(1743-1788 \mathrm{~cm}^{-1}\right)$ to $(-\mathrm{C}=\mathrm{O}$ str, ester $),\left(1163 \mathrm{~cm}^{-1}-\mathrm{C}-\mathrm{O}\right.$ str, ester $)$ and (1581$\left.1529 \mathrm{~cm}^{-1}\right)$ to heteroaromatic ring $(\mathrm{C}=\mathrm{N})$.

FTIR spectrum of PE6: The FTIR spectrum of PE6 as shown in (Fig. 14) which indicates absorption band at (3122 $\mathrm{cm}^{-1}$ ) to (aromatic $-\mathrm{CH}$ stretching), absorption bands around (1651-1638 $\mathrm{cm}^{-1}$ ) show the presence of the aromatic ring, (1529 $\left.\mathrm{cm}^{-1}\right)$ to vinyl segment, $\left(1782-1747 \mathrm{~cm}^{-1}\right)$ to $(-\mathrm{C}=\mathrm{O}$ str, ester $)$, $\left(1178 \mathrm{~cm}^{-1}-\mathrm{C}-\mathrm{O} \mathrm{str}\right.$, ester) and $\left(1579-1527 \mathrm{~cm}^{-1}\right)$ to heteroaromatic ring $(\mathrm{C}=\mathrm{N})$.

${ }^{1} \mathrm{H}$ NMR spectrum of PE6, is shown in Fig. 15 assigns the following chemical shifts; $\delta(2.5) \mathrm{ppm}$ for DMSO, $\delta(5.7), \delta$ (6.7 -8.0) ppm (s, H ) for Ar-H group.

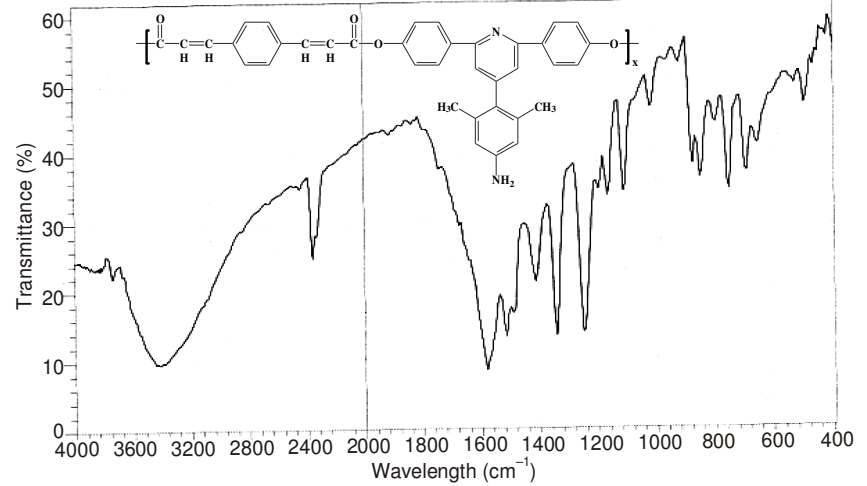

Fig. 13. FTIR spectrum of PE5

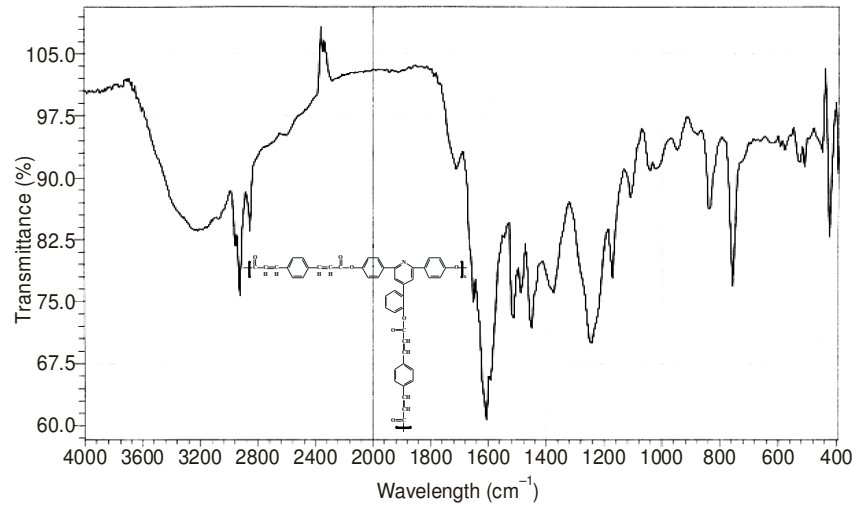

Fig. 14. FTIR spectrum of PE6

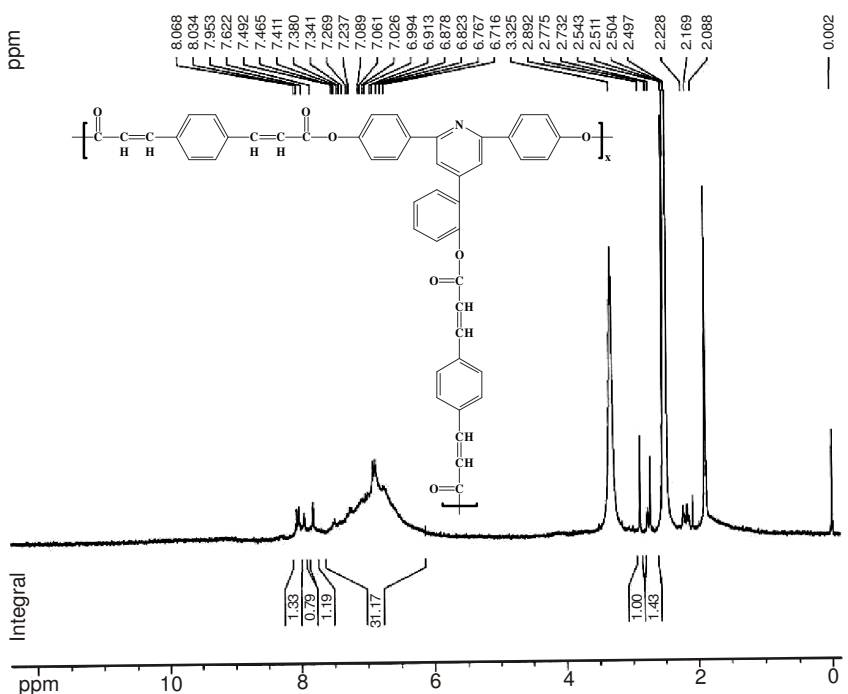

Fig. 15. ${ }^{1} \mathrm{H}$ NMR spectrum of PE6

Solubility of polyesters: Solubility of polyesters PE1PE6 was qualitatively tested in organic solvents and the results are summarized in Table-3. The method that attempt to enhance their process abilities and solubilities were either by introducing bulky groups, flexible linkages, or molecular asymmetry into the polymer backbones. In this work, the attachment of bulky pendant groups in polymer backbone not only could provide an enhanced solubility because of decreased packing density and crystallinity, but also could impart an increase in $\mathrm{T}_{\mathrm{g}}$ by restricting the segmental mobility ${ }^{18}$.

One of the major objectives of this work was producing polyesters with improved solubility. The solubility was investi- 
TABLE-3

SOLUBILITY OF POLYESTERS: PE1-PE6

\begin{tabular}{|c|c|c|c|c|c|c|}
\hline \multirow{2}{*}{ Solvent } & \multicolumn{6}{|c|}{ Polyesters } \\
\hline & PE1 & PE2 & PE3 & PE4 & PE5 & PE6 \\
\hline DMAc & +- & ++ & ++ & ++ & ++ & +- \\
\hline DMF & +- & ++ & ++ & +- & ++ & ++ \\
\hline NMP & ++ & +- & +- & ++ & +- & ++ \\
\hline Pyridine & +- & ++ & +- & ++ & ++ & +- \\
\hline$m$-Cresol & ++ & +- & +++ & +++ & +- & ++ \\
\hline $\mathrm{THF}$ & +- & +- & +- & +- & +- & +- \\
\hline $\mathrm{CHCl}_{3}$ & +- & ++ & ++ & ++ & ++ & +- \\
\hline $\mathrm{CH}_{2} \mathrm{Cl}_{2}$ & ++ & ++ & +- & +- & +- & ++ \\
\hline DMSO & ++ & +++ & ++ & +- & ++ & ++ \\
\hline Conc. $\mathrm{H}_{2} \mathrm{SO}_{4}$ & +- & ++ & ++ & +- & +- & ++ \\
\hline
\end{tabular}

gated as $(0.03 \mathrm{~g})$ of polymeric sample in $(3 \mathrm{~mL})$ of a solvent. All of the newly synthesized polyesters have good soluble in common polar and dipolar aprotic solvents without need for heating.

\section{Conclusion}

Polycondensation polymerization between di- and tri hydroxyl monomers was possible with dibutyltin dilaurate as catalysts for synthesis of polyesters containing methylene unit, Schiff-base linkages and pyridine hetero cyclic ring with 4phenylenediacrylic acid and malonic acid, respectively at $160{ }^{\circ} \mathrm{C}$ for $1 \mathrm{~h}$. The polymers were characterized by proton nuclear magnetic resonance spectroscopy and infrared spectroscopy confirmed the molecular composition of four strictly alter-nating, highly ordered polyesters having methylene chains as flexible spacers and phenylene or pyridine heterocyclic groups as the rigid segments. In this work, the attachment of bulky pendant groups in polymer backbone not only could provide an enhanced solubility because of decreased packing density and crystallinity, but also could impart an increase in $\mathrm{T}_{\mathrm{g}}$ by restricting the segmental mobility.

\section{REFERENCES}

1. U. Edlund and A.-C. Albertsson, J. Adv. Drug Deliv. Rev., 55, 585 (2003).

2. H. Carothers, J. Am. Chem. Soc., 51, 2548 (1929).

3. H. Carothers and A. Arvin, J. Am. Chem. Soc., 51, 2560 (1929).

4. A. Takasu, Y. Oishi, Y. Iio, Y. Inai and T. Hirabayashi, J. Macromol., 36, 1772 (2003).

5. W. Liu, B. Chen, F. Wang, T. Tan and L. Deng, Process Biochem., 46, 1993 (2011).

6. K. Ober and L. Bluhm, Polym. Bull., 15, 233 (1986).

7. C. Ramireddy, S. Reddy, P. Munk and N. Wu, Macromolecules, 24, 1387 (1991).

8. D. Sek, A. Woliska and H. Janeczek, J. Polym. Mater, 3, 225 (1986).

9. J. Economy, Proceedings of China-USA Bilateral Symposium on Polymer Chemistry and Physics, Beijing, p. 221 (1979).

10. T. Yamanaka, H. Ohme and T. Inoue, Pure Appl. Chem., 79, 1541 (2007).

11. A. Rahimi and S. Farhangzadeh, Iran. Polym. J., 10, 29 (2001).

12. I. Kaya, A. Bilici and M. Sacak, J. Inorg. Organomet. Polym., 19, 443 (2009).

13. B. Tamami and H. Yeganeh, Polymer, 42, 415 (2001).

14. B. Tamami and H. Yeganeh, Polymer, 38, 933 (2002).

15. S. Mehdipour-Ataei and H. Heidari, Macromol. Symp., 193, 159 (2003).

16. S. Mehdipour-Ataei and N. Bahri-Laleh, Iran. Polym. J., 17, 95 (2008).

17. D.H. Guimarães, M.M. Brioude, R.P. Fiúza, L.A.S.A. Prado, J.S. Boaventura and N.M. José, Mater. Res., 10, 257 (2007).

18. X. Zhao, C. Wang, L. Chen and M. Zhu, Colloid Polym. Sci., 287, 1331 (2009). 